metallurgy, in which Sir George Beilby's special interests lay, and in general they are given to relatively young scientists for work over a period of years.

Dr. Richardson's award is for his work on the thermodynamic properties of high-temperature sys. tems, with special reference to iron-smelting and steelmaking. After graduating in 1933 from University College, London, he did research there and at Prince. ton University and then joined the Royal Navy at the beginning of the Second World War. On demobilization in 1946 with the rank of commander, he joined the British Iron and Steel Research Association and worked on the thermodynamics of iron and steelmaking, extending his interests to the pyro-metallurgy of non-ferrous metals when he joined, in 1950, the Imperial College of Science and Technology, I London, as Nuffield Fellow to establish the Nuffield Research Group in Extraction Metal. lurgy. The work of Dr. Richardson and his colleagues has covered solutions in iron, copper and lead and molten salts and silicates, especially the chemistry of sulphur dissolved in molten silicates as sulphide and sulphate. New measurements have been made of the activities in the iron-carbon system and of the influence of chromium on the activity coefficients of carbon and silicon in molten iron. These and other studies have been particularly important in elucidating the reaction equilibria of the blast furnace, in deoxidation and during carbide formation in cooling metal.

Dr. Wormwell, whose award is for his work on surface reactions, with special reference to the mechanism of metallic corrosion, oxidation and passivation processes, graduated in 1926 from the University of Manchester and has spent his research career to date at the Chemical Research Laboratory, Teddington, where he is now senior principal scientific officer and head of the Corrosion of Metals Group. Much of his earlier published work dealt with studies of the mechanism of metallic corrosion in salt solutions and natural water, with special reference to the influence of oxygen supply, temperature, pressure and movement, by means of accurate rate-measurements over long periods in carefully controlled conditions. He worked jointly on oxide films formed on mild steel and stainless steel at ordinary and elevated temperatures, and the development of improved methods of stripping films from the metal substrate. This has involved corrosion studies of moving specimens, high-speed-rotor and electrochemical tests of painted steel, cathodic protection, corrosion inhibitors (particularly sodium benzoate) and underground corrosion and its prevention.

\section{Meteorology and Geographical Features of the Antarctic}

The discovery by the United States Antarctic Expedition of a great trough flanked by mountains 12,000-15,000 ft. high in the Antarctic ice-cap between Victoria Land and Wilkes Land, reported by Dr. Paul Siple, of the Expedition, in The Times of March 6, if confirmod, will arouse particular intorest in meteorological circles in Great Britain. The trough was roported as lying between a range of mountains roughly along the $160^{\circ} \mathrm{E}$. meridian and another high mountain wall about 200-300 miles to the west. The floor of the trough was at 7,000$9,000 \mathrm{ft}$. above sea-level. The probable existence of such a mountainous channel in the lofty ice-covered interior of Antarctica in the sector indicated was predicted last year by Mr. H. H. Lamb, of the Meteorological Office, and Commander G. P. Britton jointly in a paper (Geog. J., 349; September 1955) quoting evidence of strong topographical effects on the atmospheric circulation in the Antarctic, and had previously been suggested in more general terms by Lamb (Met. Mag., 111; 1948). Peculiarities of wind flow are often explicable from the geography of the regions in which they occur, but this is believed to be the first time that the argument has been successfully used in reverse and meteorological evidence used to predict the discovery of a major geographical feature.

The meteorological evidence is also thought by Lamb (Geog. $J ., 59 ; 1948$ ) to point to the existence of a mountain range or ice-cap crest of the order of $12,000-15,000 \mathrm{ft}$. or more in height in the heart of the hitherto unvisited region of 'East Antarctica' ; the suggested approximate position and alignment were in the region about $80^{\circ} \mathrm{S} ., 80^{\circ} \mathrm{E}$., and parallel with the $140^{\circ} \mathrm{E}$. meridian. There are indications also of low-lying regions in some parts of East Antarctica (W. Schmitt, Notos, 193 ; Pretoria, 1952) sufficiently extensive for the accumulation of deep cold air masses which acquire significance in the general circulation of the atmosphere over the Southorn Ocean. Meteorologists thus have a strong interest in the discovery of the main geographical features of the still unexplored parts of Antarctica.

\section{New Out-station for the Atomic Energy Research Establishment}

THE Atomic Energy Authority is acquiring two built-up areas on Grove Airfield, near Wantage, as a site for a small out-station of the Atomic Energy Research Establishment, Harwell. These two areas are part of the airfield which the Air Ministry had decided to relinquish. The new out-station is mainly to provide laboratories to allow the Technological Irradiation Group to develop more rapidly. This Group, a part of the Harwell Isotope Division, was formed in June 1955 in order to assist industry in making full use of the large amounts of radioactive material which will become available from the expanding atomic energy programme. The additional laboratories at Grove are seven miles from Harwell and less than two miles from Wantage. In the choice of the new out-station preference was given to sites which had existing buildings so that the work of the new group could be advanced as rapidly as possible. The location of the Technological Irradiation Group at Grove, rather than at Harwell, will reduce the formalities for those who wish to use the irradiation facilities, and so make it easier for industry to cooperate to the full. No radioactive waste will be discharged, as any small quantities which may arise will be transferred to the main plant at Harwell for treatment and disposal. A similar system has been used by the Radiochemical Centre at Amersham, and has proved to be satisfactory in practice. Later it is proposed to transfer the Isotope School from Harwoll to the new site on Grove Airfield.

\section{Course of Nuclear Engineering at the University of Glasgow}

AN undergraduate course in nuclear engineering, primarily for final-year students in the mechanical and electrical branches of the Engineering Faculty, has been in operation at the University of Glasgow since the beginning of the present session. The course prevides a general background of nuclear and reactor 